\title{
SPEECH ABNORMALITY OF THE SCHIZOPHRENIC CHARACTER IN MIDDLE SCHOOL MOVIE
}

\author{
Ilmiatul Hasanah \\ Al Izzah International Boarding School Batu, East Java \\ ilmiatulhasanah8@gmail.com
}

\begin{abstract}
Speech abnormality is one of the effects of schizophrenia. Schizophrenia is a mental disorder caused by the imbalance of neurotransmitter levels in the brain. The brain has the most crucial role in language process, this affects the content of the message to be conveyed. Therefore, this study aimed to analyze speech abnormality of schizophrenic's main character in Middle School movie. This study observed the types of speech abnormality of Rafe as the main character in the Middle School film. There were two objectives in this research; first, to identify the speech abnormality found in the Rafe's utterances in the movie; second, to identify how Rafe's utterances hindered the process of conveying information. Based on the analysis of speech abnormality, the finding revealed that Rafe experienced all types of speech bnormality. Based on Liddle's theory, these types included poverty of speech, weakening of goal, looseness, peculiar logic, peculiar sentence, peculiar word, preservation of ideas, and distractibility. This classification was based on Liddle's theory (2002). The researcher also used Carter's (2019) theory about languages influenced by the brain. The article concludes with a few suggestions to help people understand more clearly the types of schizophrenic speech abnormality.
\end{abstract}

Keywords: schizofrenia, speech abnormality

\section{INTRODUCTION}

Schizophrenia is a mental disorder caused by the imbalance of neurotransmitter levels in the brain. The brain has the most crucial role in language process, it affects the content of the message to be conveyed. Schizophrenics had the difficulty in distinguished reality and imagination from his mind. Besides, schizophrenics also had a problem with processing speech (Willy, 2018). They had a problem in thinking that affected the way they think, which also affects their speech or having speech abnormality (Thompson in Maina et al., 2019).

Speech abnormality is characterized by an inability to have an interactive dialogue, understand other people's speech, express their thoughts through the ability to speak, or 
convey it through written language. Some characteristics of speech abnormalities included using the incorrect words, inability to express opinions, inaccuracy in use grammatical patterns, minimal vocabulary, and inability to follow instructions. It also concerns to difficulty in regulating syntax (Poplack in Maina et al., 2019).

According to Carter (2019) all human activities carried out in daily operations are controlled directly by the brain. When humans want to talk or do something, the brain is motivated to control it. Besides, brain also functions as one of language processing that controls how to use language so that it can be easily understood. In this case, language acquisition is essential and influential in the addition of information received by the brain (Carter, 2019). Many theories state that language processing is a process that is entirely carried out in mind.

The relationship between language and the brain can be suspected by damage to the brain. The existence of this damage can cause language disorders. The language produced by humans is heard by the physiology of speakers and listeners. If the physiology tools of the speaker and listener have a healthy and normal condition, then the semantic message sent can also be received well. It affects the process of achieving information (Indah, 2017). A human brain is a tool that can control all the activities in daily life. Humans can be listeners as well as speakers because language is reciprocal, they can hear and talk to each other to communicate. Theoretically, the language process lasts very long, but the actual speaking process takes place in a limited time (Indah, 2017).

There have been several previous studies on schizophrenia. Astuti (2014) discusses the speech abnormalities in patients who experience schizophrenia. She found that schizophrenics have some problems which are different between one and another. One of the research subjects only experiences three symptoms of schizophrenia such as auditory, visual, and tactile hallucinations. It is caused by differences in the types of case which can damage the brain.

Another study about schizophrenia was conducted by Alkhulaib (2018) focusing on how humans understand, acquire, and produce a language. It also shows how the language processed and represented in the human brain. This is related to someone who has schizophrenia disease from thought disorders which leads to their language disorder. Thus, the abnormalities performed by schizophrenics can be identified.

Netra (2009) found that schizophrenic language by three schizophrenic patients involves several stages, such as conceptualization, formulation, articulation, and selfmonitoring. Schizophrenic patients fail to use the step of language production. While semi-calm patients were using the language production step inconsistently, calm patients used the language production step freely propagated. In anxious patients who are restless, there is a complete and blurred sound and form of language, as well as the overall meaning, so that the utterance issued by the schizophrenic patient is abysmally and disconnected. In semi-quiet patients, without phonology, morphology, syntax, and the text used is inconsistent from the beginning to the end of the conversation. In calm patients, language production is no doubt in phonology, morphology, syntax, and text. 
Nugroho (2013), discussed schizophrenic main character in A Beautiful Mind movie. The difficulties of understanding in schizophrenics is the main focus of this study. His research used descriptive qualitative which describes language disorders. It also analyzed the various forms of sentences as language disorders in schizophrenics spoken by John Nash. The types of disorders understood and context represent ways to verify data using Ginsberg's theory.

Puspitasari (2014) discussed the language produced by a schizophrenic character in the film The Soloist. It identified the situation where Nathaniel Anthony Ayers shows abnormalities in the language. She found three findings that indicated abnormalities of schizophrenia in producing language that is activities triggered by change, anxiety, and interest in music.

This study concerns with schizophrenia in the main character of Middle School movie. Rafe is the name of the main character suffering schizophrenia. He has an imaginary friend named Leo, who always supports anything about his decision and also helps his mission to destroy all the rules in his school. It is because no one supported Rafe even his mother. Accordingly, this research has a new insight into schizophrenia disease which has the fact that speech can be an expression of human thought, because in schizophrenic the phenomena of hallucination and delusion are rarely explained.

The researcher's reason for studying the sentence structure of the schizophrenics is to prove the truth that language and brain have the connection. Whenever the mind has disturbance, the speech is affected. It can be proven by the process of speaking and describe how the sentence structure of schizophrenics. These aspects belong to the discussion of psycholinguistics (Indah \& Abdurahman, 2008).

\section{METHOD}

The study focuses on analyzing utterances produced by a schizophrenic character. The subject to be analyzed is the main character of Middle school movie released in 2016 and produced by CBS Films. Rafe is the name of the main character suffering schizophrenia. He had an imaginary friend named Leo, who always supports and helps him. To get the data which used to be analyzed, the researcher learned and compared the transcripts with the scene of the movie. The researcher took the data in the form of utterances which are produced by Rafe Katchadorian as the main character. In other words, the utterances produced by Rafe contains some uniqueness in producing words, and it shows the classification of the types of speech abnormality.

In order to get a depth analysis, this study used a descriptive qualitative approach because the researcher wanted to make a detailed description and made the reader easy to understand the gist of this research. Moreover, to conduct this study, the data that has the speech abnormality were analyzed using the theory of Liddle's (2002) theory. Then, the researcher analyzed how speech abnormality hindered Rafe to convey the information by employing the theory of Carter (2019), about brain and language. 


\section{FINDING AND DISCUSSION}

The speech abnormality performed by Rafe as schizophrenic's character is classified according to the theory Liddle et al. (2002). Based on the data, the researcher found some unique words and sentence spoken by Rafe as the main character in the movie. The analysis covers several sections: poverty of speech, weakening of goal, looseness, peculiar words, peculiar sentence, peculiar logic, preservation of ideas, and distractibility.

\section{Poverty of Speech}

The poverty of speech is a condition where someone speaks with minimal sentences and does not provide more conveying information to another person. Someone who has schizophrenic disorder has the characteristics of speaking less but many things they want to convey so that information is not transmitted completely. The poverty of speech can be seen from the amount of speech experienced by someone who has a schizophrenic disorder (Liddle et al., 2002). People who have schizophrenic disorders tend to talk less and give shorter responses when speaking or answering reactions from others. This reaction is caused by a decrease in brain function that affects their social interactions experience.

People with schizophrenia are more active when they interact with people or characters in their imaginary world. This symptom was caused by an imbalance of the brain that makes hallucinations, delusions, and unclear reasoning (Indah, 2017). The symptoms of poverty of speech were found in datum 1 and 4 . In datum 1, Rafe only said the word "Thanks" when her mother said, "we don't have to take this. You know hon, I have to say, really impressive updates for the Vinlonthian Star Cruiser ". In this case, Rafe answered her mother's question very briefly and did not give a clear enough response to the statement made by his mother.

Then in datum 4, when the Vice Principal asked: "Excuse me, is your name David?" Rafe only answered the question with "No," then the vice principal asked again, "Were you carved by Michelangelo?" Rafe still explains "No" without giving any explanation. This sentence shows the existence of symptoms of poverty of speech because the other person wants comments and other answers, not only yes or no in answer.

\section{Weakening of Goal}

The weakening of goal is a condition where someone with a schizophrenia disorder has difficulty in conveying the message of the information to be transmitted. In this case, someone who has schizophrenia has difficulty processing words to be informative (Liddle's, 2002). Someone who has schizophrenia tends to answer or respond to questions or conversations with many words that he uses but does not contain information that he will convey so that it does not find the purpose of the conversation (Black and Andreasen, 2010)

The weakening of goal occurs in datum 8. When Jeanne said, "That means that it's spreading to other schools," then Rafe answered, "Hey ... um ... do you want to know a secret? I ... Anonymous. You are anonymous. Actually ... I'm really just drigging your booots! Good job. God 
Coice. "It shows that Rafe's speech is not informative but used many words that have no purpose.

\section{Looseness}

Looseness occurs when someone with a schizophrenic disorder lose their ideas. The characteristic of looseness is losing thoughts, weak ideas, and replacing ideas that will be conveyed with new ideas. Looseness can be characterized by derailment. It is a speech pattern in which the concept of a conversation delivered out of its original purpose (Liddle et al., 2002). According to Rule (in Agustina, 2014), derailment occurs when someone who has schizophrenia has an answer or related statement, but he makes a different conclusion. This symptom happens because people with schizophrenia do not make cohesion with questions or statements. So that when the idea slipped into another idea, it makes other people feel confused.

Looseness isfound in datum 6 and 8. In datum 6, when Principal Dwight say "Art should be locked up in a museum where old people can enjoy it or children on field trips" Rafe answer "We get to go on field trips to an art museum? " from the conversation Rafe talks by replacing ideas with new ideas. What Principal Dwight said cannot be understood. Rafe answered in another context but still in the same topic "museum". It can be proven when he also talks about museums. This situation has a different context from what is mean by Principal Dwight.

In datum 8, when Jeanne said, "That means that it's actually spreading to other schools," Rafe answered, "Hey ... um ... do you want to know a secret? I ... Anonymous. You are anonymous. Actually... I'm really just drigging your booots! Good job. God Choice. " From the conversation between Rafe and Jeanne, Rafe responded to Jeanne with a conversation that had nothing to do with the previous sentence. It shows that the weakening of an idea can be seen in symptoms looseness. From the context of looseness, Rafe's utterance is categorized as derailment because he had irrelevant answer.

\section{Peculiar Word}

According to Liddle's (2002), peculiar word happens when someone with schizophrenia creates the new word. People who experience schizophrenia, sometimes creating new words or terms in their language. New words created by people with schizophrenic disorders. Peculiar word in schizophrenic has its meaning and are known only to themselves. However, the word used has an unusual pattern and is not contained in any dictionary. It makes other people feel confused about the new word used by people with schizophrenia. So other people have to ask what the word means.

Peculiar word is the use of words with new structures and patterns that are not found in any dictionary. The purpose of the name is one of the symptoms experienced by someone who has schizophrenia. In this study, the researcher found one use of foreign words found on datum 7. 
In datum 7, Rafe mentioned the word "Grak-Tung," which means " victory is ours." This word is the motto that Rafe said when he managed to do something according to his plan. He got the name along with his imaginary friend, Leo. In this utterance, Rafe said the word "Grak-tung" when he was doing out his mission. Rafe gets the word "grak-tung" with Leo and no one knows about the word "Grak-tung" except Rafe and Leo.

\section{Peculiar Sentence}

The peculiar sentence is a condition where people who have schizophrenia disorder produce unusual sentences. People who have schizophrenia tend to construct sentences that are more difficult and not easily understood. (Liddle et al., 2002). Peculiar sentence is found in datum 8 when Rafe says, "Hey ... um ... do you want to know a secret? I ... Anonymous. You are anonymous. Actually ... I'm really just drigging your booots! Good job. God Choice." The sentence that he uses is not well structured and has no meaning, so the other person cannot fully understand what he is talking about. Rafe also makes a chain of semantic associations such as "I Anonymous, You are anonymous."

\section{Peculiar Logic}

Peculiar logic is a condition where someone with schizophrenia has illogical thoughts. In other words, the conclusions produced have false logic or cannot be understood logically (Liddle et al., 2002). This peculiar logic refers to a wrong end where the conclusion is derived from the wrong premise. Logic Peculiar occurred in datum $\mathbf{2 , 3}, \mathbf{5}$, and 9.

In datum 2 when his mother said "Look, I know it's hard, starting a new school mid-semester, and I don't want to take this away from you, but you have to promise me you won't spend every waking, sleeping moment waking on this when there's a whole big world out there "then Rafe answered," Mom there's a whole big world in there too." This utterance shows that the word "world" that is meant between Rafe and her mother is different between the real world and the world of imagination.

In datum 3, when Principal Dwight said: "Well, being new does not entitle you to swagger in here with no clothes on." It means that Rafe has to wear clothes according to the dress code rules. In this case, Rafe has illogical thoughts. It can be proven when he answers, "I' $m$... I'm wearing clothes". In this context, Rafe's answer would not be necessary. Principal Dwight also knows that Rafe is wearing clothes, so it doesn't need to be explained.

In datum 5, when Principal Dwight says, "Son, as a principal, I think of myselfas the father of this school, and there's nothing I wouldn't do to protect a child. Do you follow me? " then Rafe answered, "Sure, yeah, you think the students are your children." It shows that what Rafe think about children is not the same as what Principal Dwight's mean. Rafe believed that all students are the children of Principal Dwight. It shows that Rafe's thinking cannot be understood logically.

In datum 9, Rafe explains about his logical thinking, Mr. Teller and all of the student seems surprised. Because in Rafe's imagination, no one has that kind of life. When Rafe 
says, "he keeps eating and eating until he gets so fat, that he just sort explodes" that sentence is impossible to happen in real life. Rafe's statement identified as peculiar logic because expressed illogical thinking.

\section{Preservation of Idea}

Preservation of ideas occurs when someone with schizophrenia has a repetitive style of language. The repetition is in the form of words that are not grounded. Generally, the preservation of ideas is used for unwarranted words. However, some phrases or words are used as pauses for the language style (Liddle et al., 2002).

Preservation of ideas is a sign that people who have schizophrenia have a repetitive structure of words. In general, this repetition is pronounced correctly but has no meaning. However, some words are also used as pauses when speaking (Liddle et al., 2002). Preservation of ideas is found in datum 8. Rafe said, "Hey ... um ... do you want to know a secret? I ... Anonymous. You are anonymous. Actually ... I'm really just drigging your booots! Good job. God Choice. "The pronunciation of the word "Anonymous" is repeated twice and has no meaning, so this word is not needed if there is no reason.

\section{Distractibility}

Distractibility is a condition where a schizophrenic disorder tends to talk out of the topic of conversation. The idea in a schizophrenic mind is usually easy to switch from one topic to another. Sometimes, the patient changes the subject to the nearest subject. In other words, his attention is easily distracted by objects or other things that are nearby. According to Liddle's (2002), distractibility is characterized by the appearance of other ideas in a person's brain. It causes a change of topic during the communication process. Foreign ideas arise from external stimuli in the human brain. Based on Black and Andersen (2010), the distractibility has thoughts that are easily transferred from one topic to another. Usually, thepatients stop in the middle of a conversation suddenly or change the subject.

Distractibility was found in datum 8 when Jeanne spoke, "That means that it's actually spreading to other schools, "then Rafe changed the topic by answering, "Hey ... um ... do you want to know a secret? I... Anonymous. You are anonymous. Actually ... I'm really just drigging your booots! Good job. God Choice." It occured when Jeanne talks about something that has spread in other schools, then Rafe diverts the topic by talking about a secret.

The summary of the result based on the analysis above is presented in Figure 1. It describes the types of speech abnormality in Rafe's utterances who has schizophrenia. The type is classified based on Liddle's theory (2002). 


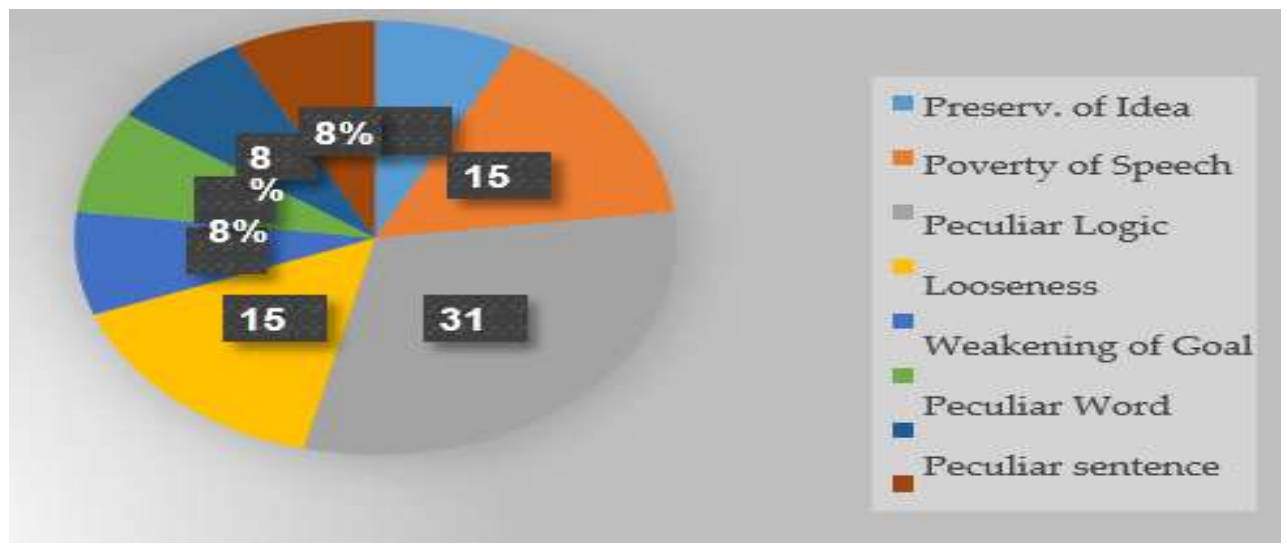

Figure 1. The Types of Speech Abnormality

\section{CONCLUSION}

Based on the analysis of this study, the researcher concludes that people with schizophrenia have a significant problem. The problem is difficulty in conveying information and receiving information properly. As a schizophrenic person, Rafe showed all the types of speech abnormality. He tends to use language that makes no sense and difficult to understand. His imaginary world is always inherent in his mind, and it influences his communication. Thus, Rafe often heard some utterances of his imaginative friends. This situation makes other people feel confused and have to reiterate what they mean to avoid misunderstanding. It proves that speech abnormalities hinder the schizophrenic in conveying the message.

In this case, the researcher found that the dominant speech abnormality is the peculiar logic. All of the symptoms of speech abnormality hinders Rafe in conveying the message. People who have schizophrenic disorder tend to have illogical speech and repeated. This symptom affects the meaning of delivering the information makes misunderstanding of the others. Some symptoms can be understood, but when Rafe shows strange sentences or words, other people feel confused, so they have to ask again.

In this study, the researcher found that Rafe, as a schizophrenic person, had a different speaking style than others. Thus, it is suggested that people talk more interactively and better understand the condition of those suffering from schizophrenia. Because people who have schizophrenic disorders tend to find it difficult to distinguish between the real world and the hallucinatory world, this situation really affects how they talk. They often bring the situation in their imagination to the real world. Therefore, the researcher suggests that this study can be used as a reference to understanding what schizophrenics try to convey.

The researcher also wrote suggestions for the future researcher in examining research related to schizophrenia to discuss the type more detail. The next researcher can also use other theories that elaborate on the types and symptoms with more adequate explanations. 


\section{REFERENCES}

Agustina,F.D (2014). APsycholinguistic Analysis ofSchizophrenicSpeechand Behaviour Portrayed in The Main Character in Canvas Movie. Universitas Negeri Yogyakarta Alkhulaib, (2018). Nathaniel Ayers' Schizophrenia In Joe Wright's The Soloist: A Psycholinguistic Study. Universitas Negeri Yogyakarya

Astuti, S. (2014). A Psycholinguistic Analysis of Schizophrenic Conversations of The Main Character in The Uninvited Movie (Doctoral dissertation, Yogyakarta State University).

Black, D. W.\& Andreasen, N. C.(2010). Introductory Textbookof Psychiatry (Fifth Edition). Arlington: American Psychiatric Publishing Inc.

Carter, Rita. (2009). The Human Brain Book. Penguin.

Indah, R.N. (2017) Gangguan Berbahasa. UIN Maliki Press

Indah, R.N. and Abdurrahman. (2008). Psikolinguistik: Konsep E Isu Umum. UIN Press Liddle, P. F., Ngan, E. T., Caissie, S. L., Anderson, C. M., Bates, A. T., Quested, D. J., ... \& Weg, R. (2002). Thought and Language Index: an instrument for assessing thought and language in schizophrenia. The British Journal of Psychiatry, 181(4), 326-330.

Maina, J., Kirigia, E. K., \& Onyango, J. O. (2019). Language and Neuropsychiatric

Disorders: An Analysis of Communication among Trilingual Schizophrenics in

Nakuru Level Five Hospital in Nakuru County, Kenya . Editon Consortium Journal of Media \& Communication Studies (ECJMCS) , 1(3), 37-37.

Netra (2009). Perilaku Seksis Dalam Bahasa Seni Pertunjukan Ragam Humor Di Kota Denpasar Kajian Bahasa Dan Jender. Jurnal Bahasa dan Sastra 5(1).

Nugroho, S. A. (2013). A Psycholinguistic Study on Comprehension Disorder of the Schizophrenic Main Character in a Beautiful Mind Movie. Jurnal Ilmiah Mahasiswa $F I B, 1(1)$.

Puspitasari, (2016). Language Production of a Schizophrenic Character In The Sociolist Movie. Universitas Brawijaya 
116 I Ilmiatul Hasanah 